\title{
Linguistic Analysis of High-Tech Production Complex
}

\author{
Aleksandr Mikhaylovich Batkovskiy1 \\ Mikhail Aleksandrovich Batkovskiy² \\ Elena Georgievna Semenova ${ }^{3}$
}

\author{
Alena Vladimirovna Fomina1
}

Evgenii lur'evich Khrustalev4

\begin{abstract}
${ }^{1}$ Joint Stock Company "Central Research Institute of Economy, Management and Information Systems "Electronics", Moscow, Russian Federation

2Federal State Unitary Enterprise "Mytishchi Research Institute of Radio Equipment", Moscow, Russian Federation ${ }^{3}$ The Department of Innovation and Quality Management, St. Petersburg State University of Aerospace Instrumentation, St. Petersburg, Russian Federation ${ }^{4}$ Central Economics and Mathematics Institute of the Russian Academy of Sciences, Moscow, Russian Federation Email: batkovskiy_a@instel.ru
\end{abstract}

\section{Doi:10.5901/mjss.2015.v6n4s4p130}

\section{Abstract}

\begin{abstract}
This article shows that the complex structure of the high-tech production complex, as well as the great quantity of research, technical, production, financial and economic processes therein complicate the analysis and assessment of its development by means of traditional approaches and modeling methods. Numerous experiments focusing on formalization of weakly structured phenomena, objects, situations and systems by traditional methods (e.g. operational or mathematical) ended with transformation of constructed models into theoretical abstractions which failed to reflect the reality. As a result, many classes of existing problems (defined improperly or too complicated for strict mathematical analysis) are not properly studied and solved. In order to examine such systems, we suggest to use the linguistic methodology and tools based on special computational procedures, which allow to study the weakly structured phenomena, objects, processes, situations and systems on the conceptual level. This article shows that the principal tools of linguistic modeling include hypertext, which combines the benefits of thesaurus, monograph and encyclopedia, and the cognitive map, which is a simplified schematic description of an individual fragment of a complicated phenomenon related to the studied problem. Using the linguistic analysis and forecasting, we constructed and characterized possible base scenarios of development of the Russian high-tech industry: "Unstable growth", characterized by comparatively fast growth of economic indicators and accompanied with inevitable failures; "Sustainable development", characterized by slow, but permanent development, and "Pessimistic forecast", implementation of which will not result in overcoming the crisis-related phenomena.
\end{abstract}

Keywords: high-tech production complex, linguistic modeling, analysis.

\section{Introduction}

The methodology of systemic analysis of high-tech operations in Russia and international cooperation in production of high-tech goods has not been structured yet and, generally, it applies traditional methods of consumer analysis, efficiency assessment, research and technical projections etc. developed within the research carried out by industrial enterprises. However, recently a rapid growth was observed in development of new models and methods of research of the global high-tech production complex and market, development and operation of innovative goods, services, as well as complexes and systems with the collective consumer (comprising several countries), shared use by advanced enterprises from different countries etc. (Kolchin, S.V., 2012).

Modern economic and mathematical analysis of the high-tech production complex represents a set of methods for study of relevant trends, production factors development prospects and task solution efficiency analysis models, bunched by a single complex of initial data and overall result.

In turn, the methods of analysis of the high-tech production complex include state-of-the-art research and technology forecasting tools, such as development of concepts and strategies of priority development of the most 
significant segments of this complex, methods for estimation of the demand for innovative goods and services, as well as the methods of analysis of high-tech industry development.

Systemic economic analysis of the high-tech production complex development prospects, including the methods for estimation of condition and prospects of high-tech development in Russia and abroad, is the most developed concept.

The industries comprising the high-tech production complex (being the most organized and dynamic structures integrated with the entire economy) are described by increased sensitivity to its overall condition and development trends, as the latter generate activity in the high-tech market, affect the strength of inter-branch and trans-regional cooperation ties (consolidate or destroy them), determine the innovation and investment climate in the country. Estimation of optimal volumes and rates of growth of innovative goods production, as well as maintenance and repair steps are directly related to the national interests. The necessary high-tech products should be supplied to domestic and international markets with due account for the organizational structure of relevant sectors of the economy, the volume and quality of human capital engaged therein, new innovative incentives and strategies of the competitors' industrial development.

Study of development prospects of the Russian high-tech production complex is based on utilization of the national innovative capacity model, which combines (in a systemic manner) the processes of functioning of all facilities of the complex. Development of research and technology forecasting methods, long-term and program-based macro-project development, as well as studying of program implementation processes allows to arrange the analysis of all phases of the produced goods' lifecycle from a single perspective (Nikolaeva, T.P., 2005).

Methods (practices) of assessment of specifications of high-tech production development programs (and, first of all, the most important of them - efficiency, viability and feasibility) take a special place among the macro-project development methods.

\section{Literature Review}

Due to the new requirements to organization of high-tech production complex development programs implementation on the part of the government, the systemic analysis methodology requires elaborated methods for studying of development programs realization, including the methods of monitoring, assessment of realization progress and the methods of program realization management.

However, numerous experiments focusing on formalization of weakly structured phenomena, objects, situations and systems by traditional methods (e.g. operational or mathematical) ended with transformation of constructed models into theoretical abstractions which failed to reflect the reality. Besides, craving for accuracy results in increased focus of many research projects on the tasks which have exact mathematical solution. As a result, many classes of existing problems (defined improperly or too complicated for strict mathematical analysis) are not properly studied and solved (e.g. methodology and tools for forecasting of economic and technological development of the rocket and space industry). Efficient resolution and study of such problems requires application of approximate (qualitative) estimates and rejection of increased accuracy requirements (Fomina, A.V. et al., 2014).

In recent years, the systemic analysis started to use linguistic (semantic) modeling tools based on special computational procedures, which allow to study the weakly structured phenomena, objects, situations and systems on the conceptual level (Moreno Capuchino, A. et al., 2000). It should be mentioned that the demand emerged for creation of methods for study and mastering of new linguistic tools and models with the purpose of their correct practical application (Martinez-Cruz, C. et al., 2015).

Linguistic methods of "soft" computing used in linguistic modeling provide much more possibilities for description of real phenomena as compared with the formalism of classic mathematics, and at the same time they do not allow many formally equivalent transformations of their constructions, which are admissible in mathematics, which seems to be the main advantage of linguistic modeling (Bezdan, E. et al., 2013). The models constructed using the linguistic tools of "soft" computing are attributed to the class of linguistic models with the following characteristics: the variables applied in such models are qualitative (semantic) rather than quantitative, with words and phrases in the natural language (rather than numbers) being their values; relationships between the linguistic variables are not represented by mathematical formulae, but determined linguistically - in the form of verbal expressions; efficiency criteria are set by qualitative recommendations regarding desirability, preferability or non-feasibility of obtained solution options rather than estimated in a form of mathematical functionality (Khrustalev, E.lu., 2014). Currently, linguistic models are consistently improved, new types of them emerge with many new types significantly enhancing the quality of management decisions taken with the use thereof (Estrella, F.J. et al., 2014). For example, review (made in (Morente-Molinera, J.A. et al., 2015)) of the condition and trends of development of linguistic modeling methods for solution of complicated problems of group decision making has proved the efficiency and capacity of such tools for analysis of modern high-tech production complex. 


\section{Methods}

Research methods are based on application of two main linguistic analysis options - hypertext and cognitive modeling.

\subsection{Hypertext modeling}

Principles of information models construction and the methods of systematization of data for various areas of knowledge differ due to the specific features of information of each specific type. It does make sense to use a special type of information model (non-linear text or hypertext comprising the advantages of thesaurus, monograph and encyclopedia) for systematization of large data class (Lawry, J., 2004). Hypertext has distinctive characteristics intrinsic to both fund and text, and, therefore, it can not be referred to any known method of information structuring (Letichevsky, A., 2014).

\subsubsection{Main definitions and concepts}

Traditional (one-dimensional) text interpreted as a sequence of characters considered sequentially is opposed by the "branching" text. In certain points of such multi-dimensional text, it can be read in various directions determined by information requests (Liu, J. et al., 2014).

Hypertext differs from the traditional text by the way of presentation of materials. Hypertext fragments may be arranged as a network organization or hierarchical tree, with several levels of material details and summary, its representation methods etc. Texts written in a natural language are systematized and kept according to a new principle. For this purpose, we need to depart from traditional approaches to funds construction and individual documents to nonlinear organization of materials. The user would read the text and select the required data as and when necessary. Hypertext is an array of texts, in which the names of documents (publications), sources of specific data and names of authors may be ascertained by means of special methods (Conklin, J., 1987).

Hypertext's main component is represented by the information (reference) article, including the heading, in which its topic is named, the text itself and the list of references to related articles. Contents (alphabetic index) and the list of main topics are used in hypertext for convenience purposes.

The list of main topics, including headings of the largest (in their sense) reference articles, which do not contain private or image information, is deemed as a compulsory and important component of hypertext (Engelbart, D., 1973). The list of main topics is recommended to be within one page. An optimal alternative of such list would be 5-8 easily remembered names. It would make sense to make an alphabetically arranged contents with the names of all articles included in the hypertext.

\subsection{Principles of hypertext construction}

The hypertext model is developed on the basis of the following principles.

Overall significance principle. Overall significance principle is deemed as the fundamental principle on the basis of which information articles are composed. Pursuant to this principle, reference article should include just specific data which are true for all objects which relate to its heading. General information which appears non-specific for the heading of such article, should be included in the articles with generic (wider) subject matter (Epshteyn, V.L., 1991).

Let's consider the following generic hierarchy as an example:

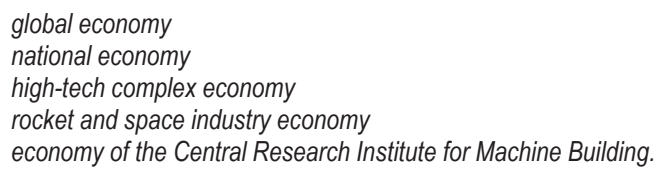

All content in the information article on any topic is fair for all its generic topics (taking into account the transitive nature of genus-species relationship).

Objectography principle. Hypertext systematizes information based on objectography principles rather than bibliography principles, where a document or publication is a unit of storage and description (Thachuk, C., 2013). In this case, a stored unit is represented by information extracted from various original sources and describing a specific class of objects or a specific object which is an item of description in the search profile. 
Life cycle principle. All objects are described by a certain life cycle - plenty of processes in which the object may be involved starting from the time of its emergence until termination of its existence. Hypertext systematization of information based on revealed life cycles of different objects is compulsory and crucial. Information about all phases of the life cycle should be documented in a form of individual articles, which should include references to the article on the source object, and vice versa (Subbotin, M.M., 1988).

\subsubsection{Hypertext thesaurus}

Thesaurus is the main element of hypertext suitable for search and systematization of information requested by the subscriber. Thesauri currently applied for working with information arrays are designed to improve accuracy and completeness of information search. Unlike traditional information search systems, there is no division of the search apparatus into the array of publications (documents) search profiles and thesaurus in hypertext. In hypertext, search tools are realized in the form of its thesaurus (Sahin, A. and Alsancak, D., 2011).

Hypertext thesaurus consists of an array of thesaurus articles. Each article has its own heading and the list of related thesaurus articles, for which the relatedness type is specified. Name of a thesaurus article coincides with the heading of relevant information article of the hypertext and is designed for identification of an object, information about which is given in the information article. Generally, object means a system, relationship, process, subject matter. Each name of an object is interpreted in hypertext as a name of a class (set) of objects related to such name (Epshteyn, V.L., 2005). Table 1 shows the symbols and signs for different types of relationships stipulated in discussed realization of hypertext.

Table 1. Types and symbols of relationships in hypertext

\begin{tabular}{|c|c|c|c|}
\hline \multicolumn{2}{|r|}{ Direct relationship } & \multicolumn{2}{|r|}{ Inverse relationship } \\
\hline Symbol & Meaning & Symbol & Meaning \\
\hline$=$ & Synonymy & $=$ & Synonymy \\
\hline $\mathrm{R}$ & Species - genus & v & Genus - species \\
\hline v & Genus - species & $\mathrm{R}$ & Species - genus \\
\hline U & Consolidation (part-whole) & $f$ & Fragmentation \\
\hline$f$ & Fragmentation & $U$ & Consolidation (part-whole) \\
\hline$n$ & Process - superprocess & e & Process - process phase \\
\hline e & Process - process phase & $\mathrm{n}$ & Process - superprocess \\
\hline$r$ & Process-role performer & c & Subject matter-process \\
\hline c & Subject matter-process & r & Process-role performer \\
\hline p & Effect and cause & S & Cause and effect \\
\hline $\mathrm{s}$ & Cause and effect & $p$ & Effect and cause \\
\hline $\mathrm{a}()$. & Other relationships (associative) & $\mathrm{a}()$. & Other relationships (associative) \\
\hline
\end{tabular}

Depending on hypertext's purpose, its thesaurus may include other sorts of relationships. Figure 1 shows an example of a thesaurus article about the economics of high-tech production complex.

Relationships with the closest related objects should be specified in the hypertext's thesaurus article. References are divided into groups which are arranged in a certain order: = (Synonymy); R (Species - genus); $\mathrm{U}$ (part - whole); $\mathrm{n}$ (Process - superprocess); v (Genus - species); $f$ (whole - part); $r$ (Process - role performer); e (Process - process phase); c (Subject matter - process); $p$ (Effect and cause); s (Cause and effect), a (associative). 


\section{R. National economy}

U. National business system

v. Economic relationship in connection with major construction operations in the high-tech production complex

v. Economic relationships of industrial and R\&D enterprises

f. Research and industrial capacity

f. Raw materials and financial resources

f. Enterprises and organizations of the high-tech production complex

f. Workers employed by the high-tech production complex

f. Researchers employed by the high-tech production complex

f. Civilian products and services

f. Dual-use products

c. Management of economic relationships in the high-tech production complex

c. Competition in the global markets

c. Restructuring and development of economic relationships in the high-tech production complex

p. Supply of innovative high-tech equipment for govemment needs

s. National economic capacity

a. Country's social and political system

Figure 1. Thesaurus article on "The economics of high-tech industry" object

\subsubsection{Comparison with other information systems}

In its functionality and structure, hypertext comes close to state-of-the-art expert systems (Lu, W. et al., 2014). In addition to the knowledge base, it has a developed interface for interaction with the user, which allows to communicate with the system in a language close to the natural language, as well as the set of tools ensuring upgrade and modification of the knowledge base. However, the specialist dealing with hypertext remains a "solver" (holder of the right to make conclusions) (Nelson, T., 1993).

Hypertext may be considered as a special kind of intellectual complexes of a new research area - knowledge delivery systems. Such complexes, as well as hypertext products possess no right to make conclusions, being unable to reason, but having a knowledge base and information comparison mechanism (Walhout, J. et al., 2015).

Convergence, and in some cases amalgamation of capacities of expert, search, hybrid, hypertext and some other latest types of information systems, seems quite natural and reflects a natural process of artificial intelligence systems' integration into a single complex (Lebedev, V.V. and Zharinov, S.E., 2014). In such complex, the hypertext knowledge base transforms from an independent module into the central and compulsory unit requiring particular care in the course of its development and maintenance.

\subsection{Cognitive modeling}

With due account for the revealed peculiarities, it would be reasonable to study the processes of stable operation and progressive development of the Russian high-tech production complex on the basis of cognitive models (maps) related to the class of linguistic models (Nefedova, L.A. and Remkhe, I.N., 2014). In a general sense, a cognitive model is a simplified schematic description of an individual fragment of a complicated phenomenon related to the studied problem. The peculiarity of the cognitive modeling method, which distinguishes it from traditional methods, lies in the fact that, due to application of linguistic variables and fuzzy algorithms, it enables efficient study of the behavior of complex ill-defined systems, which are not subject to strict mathematical analysis. Cognitive models are generally applied on the strategic or conceptual level of solutions' management and development. Description of the cognitive modeling procedure is based on the strategic management of development of a random economic system or its components. Modeling is a cyclical process including five main interrelated phases: cognitive structuring, structural analysis of the cognitive model, scenario modeling of situation development, assessment and interpretation of modeling results, cognitive monitoring of situation. Figure 2.

The system of concepts, which defines a cognitive approach to forecasting and management, is shown on 


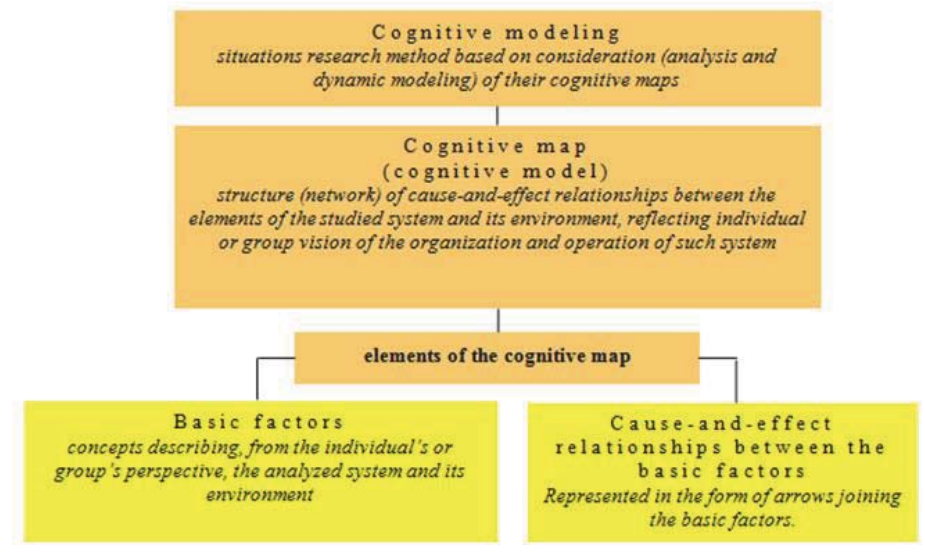

Figure 2. The system of concepts which are used in cognitive modeling

In accordance with the general theory, cognitive analysis and modeling of strategic development of the high-tech production complex includes 5 main phases.

\subsubsection{Cognitive structuring phase}

On this phase, information about operation of the high-tech production complex and its development trends (foreign and domestic policy, social and economic etc.) affecting efficiency of research and production activities of the complex is cognitively structured. This phase consists of collection, analysis and structuring (synthesis) of information and development of the cognitive map, which conceptually describes the terms and mechanisms of operation of the high-tech production complex.

Information is structured in order to create numerous basis factors $X=\left\{x_{1}, x_{2}, \ldots, x_{n}\right\}$ and to reveal cause-and-effect relationships between them. Trends demonstrated by each basic factor (change rate of the indicator which describes the object associated with a specific factor) are identified and estimated. The nature (negative or positive) and strength of the identified cause-and-effect interrelationships between the basic factors are revealed (Maksimov, V.I., 2005). The variables' values are determined based on the linguistic scale with a number from interval $[-1,+1]$.

Basic factors, cause-and-effect relationships between them, the factor values and relationships are revealed from the analysis of text data in information arrays, interviewing and questioning of experts and decision makers.

Development of a cognitive map formally means construction of a directed graph $G=(X, A)$, in which: $X$ means the vertex set, clearly corresponding to the set of basic factors; $A$ means the set of edges, showing the mutual influence of factors. On this phase, the subsets of control and target factors, as well as the vector of the basic factors' initial trends are singled out from the set of basic factors. Control factors are chosen from factors related to the external environment or control object, which may be affected by the controlling subject. Target factors are chosen from the factors which describe the condition and targets of the control object.

\subsubsection{Cognitive map's structural analysis phase}

Efficient management of a problem requires study of its structural peculiarities, i.e. detailed characteristics of cause-andeffect relationships between the basic factors. Comprehensive analysis of the map focusing on study of such characteristics includes assessment of control targets in respect of the consistency, efficiency of the aggregate effect of control factors on target ones.

Situation development scenario modeling phase may be effected in the modes of controlled development and selfdevelopment. 


\subsubsection{Modeling results assessment phase.}

In order to determine the degree of efficiency of management decisions, an indicator system is suggested for the assessment of:

- the degree of target achievement - target achievement ratio;

- level of situation's favorability for a decision maker - favorability ratio;

- $\quad$ the value and amount of the resources required for realization of planned management - resource intensity of the decision;

- management decision efficiency ratio - relationship between the target achievement level and the value and amount of resources required for its realization.

Situation's cognitive monitoring phase, which enables modification of the cognitive map, additional analysis and situation modeling in case of situation change.

\section{Results}

Main research and practical results obtained in the process of studies may be stated as follows:

1. Existing methods of analysis and projection of development of the high-tech production complex in general allows to take into account new conditions. However, in order to carry out further detailed research, we need to enhance the methods towards increase in the quantity of relevant factors, assessment of final results from provision of services for their consumers, construction of the indicators system for measurement of program implementation degree, formation of strategic targets, tactical tasks and quantitative assessment of budgetary expenses' efficiency.

2. Analysis of works dedicated to improvement in relevant methods shows that they, in general, do not require new formalized procedures which guarantee qualitative results. As a rule, solving of partially or fully nonformalized tasks is required for taking new conditions into account. Solving of such tasks requires relevant procedures, implementation of which, in turn, requires following the determined sequence of actions and meeting specific rules. Such procedures may be used for clarification of targets, tasks and priorities of innovations in the mid- and long-term. There is also another critical and difficult task - establishment of the final performance assessment system for the high-tech production complex, i.e. the methods of measurement of effect from provision of new goods and services to their consumers.

3. The developed linguistic models complex of the high-tech production complex consists of the scientific and technological model, the production model, geopolitical and socioeconomic situations models.

The linguistic model of the research and technological area of the high-tech production complex reflects interaction between the processes which accompany R\&D and design works. One of the key factors, which characterizes this complex, is its scientific and technical potential consisting of qualified research staff, scientific and technological capacity of science-intensive and high-tech production complex and material and technical base of scientific researches.

The high-tech production complex model reflects interaction between the processes which accompany creation of innovative technical equipment of civil, military and dual use. Production and sale of new goods by enterprises of the high-tech production complex are governed by market laws and determined by the demand for produced goods and services, which directly depends on competitiveness of produced goods. The latter, in turn, is determined by quality and price. Considering that imported goods are the main competitors of such products, the difference between the real and nominal RUB exchange rate is crucial for competitiveness of domestic products: the bigger such difference the higher the competitiveness.

Geopolitical and socioeconomic situation's linguistic models reflect geopolitical influence of the globalized world's system and observable trends in the national socioeconomic situation on the high-tech production complex.

4. Potential basic scenarios of development of the Russian high-tech industry are elaborated and assessed; in particular, scenarios of development of the national high-tech production complex may be represented as follows. "Unstable growth" scenario is described by comparatively fast growth of economic indicators and is accompanied by inevitable failures. "Sustainable development" scenario is described by slow but permanent development. "Pessimistic forecast" scenario represents a situation when the complex loses its capacity to implement long-term innovation programs. Overcoming the crisis is a matter of the viability of the complex (Mizyun, V.A., 2010). Inability to overcome the crisis-related phenomena results in implementation of the 
"Pessimistic forecast" scenario. Combination of general phenomena is called "Research potential - Production facilities - Restructuring - Materials - Components - Personnel" crisis. It has the systemic nature for the high-tech production complex; however, with right management, the complex may overcome the crisis with minimum losses.

\section{Discussion}

Reduction of fundamental research projects, liquidation of research institutions results in deficit of innovative knowledge and portfolio, which make possible progressive innovative development and modernization of high-tech facilities. The "Restructuring" crisis component means the crisis of a systemically important institutional factor. The Technological component of the crisis is called "Materials - Components". Consolidated, high-tech and efficient industry is filled with motivated highly trained personnel. Deficit of such personnel at different levels - industry, regional, program, enterprise and organization - is known as the "Personnel" crisis.

The first scenario, called "Unstable growth", is related to implementation of predominantly market mechanisms within the high-tech production complex. "Sustainable development" scenario focuses on sustainable development (without failures) of the industry for achievement of long-range objectives. The list of long-range objectives is determined by: national interests, market demands (consumer preferences and demand for services). General attractiveness of an industry may be estimated on the basis of the following factors: market capacity and estimated growth, cyclical fluctuations, technological condition, competitors, emerging opportunities and threats, capital requirements, average profitability of the industry, social and political factors, environmental factors, governmental regulation. The "pessimistic forecast" scenario means that high-tech production complex enterprises, facing insignificant volume of public contracts and low competitiveness, would have to terminate their core operations and to adjust for production of other (economically efficient) goods or to restructure the assets by their sale. For the country, this will mean refusal to participate in innovations as a producer of civilian goods and services - liquidation of the complex and its transformation into a special closed military form (Sokolov, A.V. and Bazhanov, V.A., 2014).

For the purposes of intensive transition of the national economy to the innovative development path, as well as in order to provide research and technological facilities for the economic component of the national security so that hightech facilities would be protected from internal and external threats and risks, and with reasonable relevant costs, we need to: develop an efficient innovation-oriented research, economic and industrial policy under the conditions of institutional and structural changes; measure, assess and forecast the economic strength of high-tech facilities of different forms of ownership and the impact of international and domestic processes thereon; increase efficiency of high-tech industries and the national research complex, which represent the basis of the modern knowledge economy; forecast desirable characteristics of future enterprises of high-tech, innovation-oriented sector of the national economy and effects of their emergence in view of increase of competitiveness of new products; assess and improve socioeconomic position of employees engaged in high-tech enterprises etc.

\section{Conclusion}

Studying of various concepts of the economic growth theory shows that a special role in maintenance of established economic trends belongs to the high-tech production complex. Investments into this complex, being the core resource of sustainable economic growth, make possible self-maintained development of the system on the basis of a positive feedback. The national innovation system of high-tech facilities, which is formed under the influence of the following factors specific for each country, should be considered as a crucial and complicated mechanism of self-development and modernization of the economy: area and availability of natural resources and labor; development of public institutions; development of education, science, technologies, culture; condition and development of research and production capacity etc.

In order to enhance efficiency and quality of project development, as well as operation, maintenance and forecasting of high-tech production complexes, their life cycle should include the information modeling phase. Traditional information presentation of the system includes integral and interrelated description of models, at least at three levels: linguistic (conceptual), logical, physical. Models are built using special methods and technologies developed for each particular level. Currently, there is no systemic, theoretically substantiated and software-implemented approach which would allow to embrace in a single cycle all processes of accumulation, systematization and modeling of knowledge on innovative development of the high-tech production complex, starting from obtaining of linguistic level models and ending with physical databases, processing programs and designer's operational documentation. Whereas the systems for 
automation of model construction processes are already developed and operate for physical and logical levels, it is difficult to specify efficient and utilized software packs among the methods and tools of linguistic projection as the most intellectual kind of activity. Lack of completely elaborated general procedure of high-tech production complex modeling is explained not just by unsolved problems, but, to a considerable extent, by enhancement of the effect and growth of importance of rapidly developed database and model theory, as well as by the need for matching of general principles of information system's development, on the one hand, with the methods of creation and utilization of databases, on the other hand. Modeling tools should provide a through-cycle when creating models of different levels allowing to make their adjustment and modernization in an integrated manner.

Improvement in the methods of linguistic analysis and forecasting of development of the high-tech production complex will allow to obtain the following research results:

1) substantiated (using a model) concept of public-private incentives in innovations at high-tech enterprises;

2) methods of logical and linguistic modeling of the strategy of innovative development of the high-tech sector of the Russian economy;

3) the knowledge base including the structured information in the form of semantic models describing the mechanisms and conditions of innovative operations of the high-tech sector;

4) organizational and economic mechanism of support and incentives for innovations implemented by high-tech enterprises;

5) methodological approaches to solving the issues related to the rights to innovation results;

6) main provisions of high-tech enterprise policies with regard to protection of created intellectual property.

7) complex of logical and linguistic methods of innovative development of the high-tech sector of Russian economy;

8) scenario-based forecast of innovative development of the high-tech sector of the Russian economy;

9) the model for financing of fundamental research for innovative high-tech enterprises;

10) modern financial instruments for compensation of innovations costs and the procedures of utilization thereof;

11) methods of coordination between the public sector and private business in creation of new innovative technologies.

12) integrated methods of providing incentives to innovations jointly implemented by high-tech enterprises and research and educational institutions;

13) methods of creation and maintenance of consulting, information, educational and legal infrastructure regarding innovations of high-tech companies;

14) methods of encouragement of industrial companies to invest in R\&D in connection with fulfillment of public contracts;

15) conceptual improvement in existing regulatory framework regarding granting of tax reliefs to innovators.

\section{Acknowledgements}

This research project was supported by the Russian Scientific Fund (RSF Project No. 14-18-00519).

\section{References}

Bezdan, E., Kester, L., \& Kirschner, P. (2013) The Influence of Node Sequence and Extraneous Load Induced By Graphical Overviews on Hypertext Learning. Computers in Human Behavior, Vol. 29, Issue 3, May 2013, 870-880.

Conklin, J. (1987) Hypertext: An Introduction and Survey. Computer, 1987, 9, $17-41$.

Engelbart, D. (1973) Design Considerations for Knowledge Workshop Terminals. Afips Conference Proceedings, 42, National Computer Conference, June 4-8, 1973, 119-131.

Epshteyn, V.L. (1991) Gipertekst - novaya paradigma informatiki [Hypertext - A New Paradigm of Computer Science]. Avtomatika $i$ telemekhanika - Automation and Remote Control, 11, 3-16 [in Russian].

Epshteyn, V.L. (2005) Elektronnaya giperkniga - novaya epokha v istorii nauki i obucheniya [Electronic Hyperbook - A New Era in the History of Science and Education]. Problemy upravleniya - Problems of Management, 5, 2-8 [in Russian].

Estrella, F.J., Espinilla, M., Herrera, F., \& Martinez, L. (2014) FLINTSTONES: A fuzzy linguistic decision tools enhancement suite based on the 2-tuple linguistic model and extensions. Information Sciences, Vol. 280, 152-170.

Fomina, A.V., Avdonin, B.N., Batkovskiy, A.M., \& Batkovskiy M.A. (2014) Upravlenie razvitiem vysokotekhnologichnykh predpriyatiy naukoemkikh otrasley promyshlennosti [Managing the Development of High-Tech Enterprises in Science-Intensive Industries]. Moscow: Kreativnaya ekonomika [in Russian].

Khrustalev, E.lu. (2014) Logiko-lingvisticheskie modeli naukoemkogo proizvodstvennogo kompleksa kak raznovidnost intellektualnykh 
informatsionnykh sistem [Logical-Linguistic Model of High-Tech Industrial Complex as a Kind of Intelligent Information Systems]. Ekonomicheskiy analiz: teoriya i praktika - Economic Analysis: Theory and Practice, 11, 11-22 [in Russian].

Kolchin, S.V. (2012) Sotsialno-ekonomicheskaya i geopoliticheskaya znachimost naukoemkikh proizvodstv [Socio-Economic and Geopolitical Importance of Knowledge-Intensive Industries]. Finansovaya analitika: problemy i resheniya - Financial Analytics: Problems and Solutions 37, 37-45 [in Russian].

Lawry, J. (2004) A Framework for Linguistic Modeling. Artificial Intelligence, Volume 155, Issues 1-2, May 2004, 1-39.

Lebedev, V.V., \& Zharinov, S.E. (2014) Innovatsionnye podkhody k sozdaniyu sistemy upravleniya vysokotekhnologichnym proizvodstvom [Innovative Approaches to the Creation of High-Tech Manufacturing Control Systems]. Innovatsii - Innovations, 1, 110-115 [in Russian].

Letichevsky, A. (2014) Theory of Interaction, Insertion Modeling, and Cognitive Architectures. Biologically Inspired Cognitive Architectures, Volume 8, April 2014, 19-32.

Liu, J., Li, W., Chen, S., \& Xu, Y. (2014) An Axiomatizable Logical Foundation for Lattice-Ordered Qualitative Linguistic Approach for Reasoning with Words. Information Sciences, Volume 263, April 1, 2014, 110-125.

Lu, W., Yang, J., Liu, X., \& Pedrycz, W. (2014) The Modeling and Prediction of Time Series Based on Synergy of High-Order Fuzzy Cognitive Map and Fuzzy C-Means Clustering. Knowledge-Based Systems, Volume 70, November 2014, 242-255.

Maksimov, V.I. (2005) Strukturno-tselevoy analiz razvitiya sotsialno-ekonomicheskikh situatsiy [Structural-Targeted Analysis of SocioEconomic Situations]. Problemy upravleniya - Problems of Management, 3, 30-38 [in Russian].

Martinez-Cruz, C., Porcel, C., Bernabe-Moreno, J., \& Herrera-Viedma, E. (2015) A model to represent users trust in recommender systems using ontologies and fuzzy linguistic modeling. Information Sciences, Vol. 311, 1 August 2015, 102-118.

Mizyun, V.A. (2010) Sovremennye podkhody k organizatsii upravleniya vysokotekhnologichnym proizvodstvom [Modern Approaches to Managing High-Tech Manufacturing]. Audit i finansovyy analiz - Audit and Financial Analysis, 4, 345-353 [in Russian].

Moreno, Capuchino A., Juristo, N., \& Van De Riet, R. (2000) Formal Justification in Object-Oriented Modeling: A Linguistic Approach. Data \& Knowledge Engineering, Volume 33, Issue 1, April 2000, 25-47.

Morente-Molinera, J.A., Perez, I.J., Urena, M.R., \& Herrera-Viedma E. (2015) On multi-granular fuzzy linguistic modeling in group decision making problems: A systematic review and future trends. Knowledge-Based Systems, Vol. 74, 49-60.

Nefedova, L.A., \& Remkhe, I.N. (2014) Towards Cognitive Modeling of the Technical Translation Process. Procedia - Social and Behavioral Sciences, Volume 154, 28 October 2014, 237-244.

Nelson, T. (1993) Literary Machines. Sausalito: Mindful Press.

Nikolaeva, T.P. (2005) Vysokotekhnologichnyy kompleks v strukture promyshlennogo proizvodstva Rossii [High-Tech Complex in the Industrial Structure of Russia]. Innovatsii - Innovations, 10, 38-43 [in Russian].

Pospelov, D.A. (1981) Logiko-lingvisticheskie modeli v sistemakh upravleniya [Logical-Linguistic Models in Control Systems]. Moscow: Energoizdat [in Russian].

Sahin, A., \& Alsancak, D. (2011) The Effect of Hypertexts with Different Lengths on Reading and Comprehension Skills of the Students. Procedia - Social and Behavioral Sciences, Volume 28, 2011, 347-354.

Sokolov, A.V., \& Bazhanov, V.A. (2014) Vysokotekhnologichnoe i naukoemkoe proizvodstvo: problemy i neopredelennost budushchego [Technology-Intensive Enterprises: Challenges and Uncertainty of the Future]. EKO - ECO, 1, 15-25 [in Russian].

Subbotin, M.M. (1988) Novaya informatsionnaya tekhnologiya: Sozdanie i obrabotka giperteksta [New Information Technology: Creating and Editing Hypertext]. NTI, 2, 5, 7-15 [in Russian].

Thachuk, C. (2013) Indexing Hypertext. Journal of Discrete Algorithms, Volume 18, January 2013, 113-122.

Walhout, J., Brand-Gruwel, S., \& Jarodzka, H., et al (2015) Learning and Navigating in Hypertext: Navigational Support By Hierarchical Menu Or Tag Cloud? Computers in Human Behavior, Volume 46, May 2015, 218-227. 